\title{
The regulatory effect of the p38 signaling pathway on valdecoxib-induced apoptosis of the Eca109 cell line
}

\author{
SHU-XIA LIU ${ }^{1}$, YU-JUN ZHANG ${ }^{1}$, HUI-FANG GUO ${ }^{1}$, JUN HAO ${ }^{1}$, QING-JUAN LIU ${ }^{1}$, \\ JUN-RU LIU ${ }^{1}$, JIAN-WEN GUO ${ }^{2}$, JIANG-HUI LIU ${ }^{2}$ and LIAN-FU ZUO ${ }^{1,2}$ \\ ${ }^{1}$ Department of pathology, Hebei Medical University, Shijiazhuang 050017; \\ ${ }^{2}$ Hebei Cancer Institute, Hebei Medical University, Shijiazhuang 050011, P.R. China
}

Received January 23, 2009; Accepted April 23, 2009

DOI: $10.3892 /$ or_00000439

\begin{abstract}
Valdecoxib is a second generation selective COX-2 inhibitor that can induce cell apoptosis in a variety of cell types, but its precise regulatory mechanism is unknown. Apoptosis of Eca109 cells and p38 mRNA expression were investigted. The expression of p-p38MAPK, Fas and FasL proteins were detected by immunohistochemical staining and FCM. Valdecoxib increased the apoptosis rate of Eca109 cells. Fas and FasL protein expression was upregulated in the valdecoxib groups, while SB203580 partly inhibited the valdecoxib-induced overexpression. Valdecoxib increased p38MAPK expression, while SB203580 inhibited the overexpression of this protein and the apoptosis rate decreased. The expression of Fas, FasL and p38MAPK protein were positively correlated with the apoptotic rate. In conclusion, valdecoxib activates the p38MAPK pathway, thus up-regulating expression of the Fas and FasL proteins, which may be one of the mechanisms through which valdecoxib induces apoptosis.
\end{abstract}

\section{Introduction}

Esophageal carcinoma (EC) is one of the major malignant tumors that has a high incidence in China and is characterized by a unique geographical distribution. Therefore, it is necessary to search for chemopreventive tools or drugs to decrease the risk of carcinogenesis of esophageal epithelial cells.

Many studies have shown that COX-2 overexpression can induce the occurrence of tumors such as esophageal, colorectal and pancreatic carcinoma tumors. COX-2-selective inhibitors have been used to treat malignant tumors via COX-2

Correspondence to: Professor Lian-Fu Zuo, Hebei Cancer Institute, 4th Hospital, Hebei Medical University, Jian-kang Road No.12, Shijiazhuang 050011, P.R. China

E-mail: susanliu2001@hotmail.com

Key words: Valdecoxib, esophageal cancer, p38MAPK, Fas, FasL, SB203580 targeting. Valdecoxib is a second generation selective COX-2 inhibitor. Our previous studies showed that valdecoxib induces apoptosis in Eca109 cells and that the mechanism may be correlated with the overexpression of apoptosisrelated genes; however, the precise regulatory mechanism of valdecoxib is unknown. The P38MAPK signal pathway plays an important role in inducing cell apoptosis.

In the present study, we investigated the effect of valdecoxib on apoptosis and the potential role of p38MAPK in its induction of apoptosis by valdecoxib on Eca109 cells.

\section{Materials and methods}

Reagents. The antibodies used for the immunofluorescent and immunohistochemical detection of the p-p38, Fas and FasL proteins were: i) monoclonal antibody (MoAb) pp38, a mouse antibody against human p-p38 (Clone D-8, Santa Cruz Biotechnology, USA; working concentration, 1:50); ii) rabbit polyclonal antibodies against Fas and FasL (Clones C-20 and N-20, respectively, Santa Cruz Biotechnology; working concentration, 1:50); iii) the secondary antibodies include FITC-conjugated goat anti-mouse and anti-rabbit IgGs (Jackson Immunoresearch Laboratories Inc., Code Number 115-095-003/115095; working concentration, 1:100). TRIzol was purchased from Sigma; AMV, dNTP, RNasin, AMV Oligo(dT)15 and Taq DNA Polymerase were obtained from Promega. Valdecoxib was synthesized by the School of Pharmacy of Hebei Bedical University (Shijiazhuang, China) with a purity of $99 \%$ and was dissolved in DMSO at $2.50 \times 10^{5} \mu \mathrm{mol} .1^{-1}$.

Cell culture. Human esophageal cancer cells (Eca109) were obtained from the Laboratory Animal Center, Fourth Military Medical University, Xi'an, China. Cells were grown under humidified air with $5 \% \mathrm{CO}_{2}$ in an incubator at $37^{\circ} \mathrm{C}$ in RPMI1640 supplemented with $10 \%$ fetal bovine serum, $100 \mu \mathrm{g} / \mathrm{ml}$ streptomycin and 100 units $/ \mathrm{ml}$ penicillin. The cells were inoculated at $1 \times 10^{4}$ cells $/ \mathrm{ml}$ in culture flask or plate. After $6 \mathrm{~h}$, the cells were divided into groups, including control,

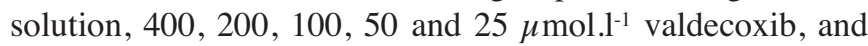
various concentrations of valdecoxib + SB203580, and cultured for $72 \mathrm{~h}$. 


\section{Detection of valdecoxib-induced apoptosis}

Flow cytometry. After treating cells with valdecoxib, attached and floating cells were pooled and centrifuged in the same tube. The cell pellets were washed with PBS containing $1 \%$ fetal bovine serum, fixed in $70 \%$ ethanol, and stained with $500 \mu \mathrm{g} / \mathrm{ml}$ of propidium iodide (Sigma) containing 3 Kunitz RNase and 1\% fetal bovine serum in PBS. Then, the stained cells were analyzed in an Epics-XLII flow cytometer (Beckman Coulter, Miami, FL).

Transmission electron microscopy. The cells were treated as described above, followed by fixation, washing, desiccation, alcoholic dehydration, embedment, and double-staining with uranyl acetate and lead citrate. In the end, apoptosis was observed with an H-7500 type transmission electron microscope.

DNA ladder assessment. Cells under different treatments were collected, washed twice with PBS, lysed in $80 \mathrm{ml}$ of lysis buffer [50 mM Tris ( $\mathrm{pH} 8.0), 10 \mathrm{mM}$ ethylenediaminetetraacetic acid (EDTA), $0.5 \%$ sodium sarkosinate, and $1 \mathrm{mg} / \mathrm{ml}$ proteinase $\mathrm{K}$ ] for $3 \mathrm{~h}$ at $56^{\circ} \mathrm{C}$, and then treated with $0.5 \mathrm{mg} / \mathrm{ml}$ RNase A for an additional $1 \mathrm{~h}$ at $56^{\circ} \mathrm{C}$. DNA was extracted with phenol/chloroform/isoamyl alcohol (25/24/1, $\mathrm{v} / \mathrm{v}$ ) before loading. Samples were mixed with loading buffer [50 mM Tris, $10 \mathrm{mM}$ EDTA, $1 \%(\mathrm{w} / \mathrm{w})$ low-melting point agarose, and $0.025 \%(\mathrm{w} / \mathrm{w})$ bromophenol blue] and loaded onto a pre-solidified $2 \%$ agarose gel containing $0.1 \mathrm{mg} / \mathrm{ml}$ ethidium bromide. The agarose gels were run at $50 \mathrm{~V}$ for 90 min in TBE buffer, after which they were observed and photographed under UV light.

Detection of p38 mRNA by semiquantitative RT-PCR. Total RNA was isolated from the cells using TRIzol following standard protocols. cDNA was synthesized using reverse transcriptase according to the instruction. Reverse transcription was performed using $2 \mu \mathrm{g}$ RNA and $0.5 \mu \mathrm{g}$ oligo(dT) primer. The cDNA was amplified in a buffer containing $1.5 \mathrm{mM}$ $\mathrm{MgCl}_{2}, 0.2 \mathrm{mM}$ of each dNTP, $0.5 \%$ DNA polymerase, and $0.2 \mathrm{mM}$ of each primer pair. The PCR conditions were as follows: the 346-bp p38 PCR fragment was primed using 5'-CGG AGT GGC ATG AAG CTG TAG-3' and 5'-CCC TAG GAA ACC AAC ACA GCA-3'. The 451-bp GAPDH fragment was primed by a 5'-CCA CAG GCC AGG CCA GCA CT-3' and 5-TCC ACC ACC CTG TTG CTG TAG-3'. PCR was conducted for 35 cycles at $94^{\circ} \mathrm{C}, 60 \mathrm{sec}$ (denaturation), $61.8^{\circ} \mathrm{C}, 60 \mathrm{sec}$ (annealing), and $72^{\circ} \mathrm{C}, 60 \mathrm{sec}$ (extension). The PCR products were examined by $1.5 \%$ agarose gel electrophoresis with ethidium bromide staining. To determine the relative levels of gene expression, semiquantitative analysis was performed by the method reported by Nakayama et al (1) and Yokoi et al (2). The optical density of each band was measured, and the background intensity was subtracted from the band density using image-analysis software (GDS-8000, UVP, USA). The ratio of the initial amount of each gene to GAPDH was compared for each group. These experiments were repeated at least twice.

Detection of p-p38, Fas and FasL protein expression by flow cytometry. Fluorescence staining was performed using indirect immunofluorescence labeling methods. For each group (control, valdecoxib and valdecoxib+SB203580), $10^{6}$ cells/ml were washed twice with PBS and incubated in a water bath for $30 \mathrm{~min}$ with $100 \mu \mathrm{l}$ of primary antibodies against p-p38, Fas and FasL. Then, the cells were washed twice with PBS and incubated in a water bath for $30 \mathrm{~min}$ at $37^{\circ} \mathrm{C}$ with $100 \mu 1$ of FITC-conjugated goat anti-mouse or rabbit IgGs. The cell suspension was washed and resuspended in $1.0 \mathrm{ml}$ PBS, filtered through a $47-\mu \mathrm{m}$ nylon mesh, and analyzed by flow cytometry. Three control samples were used: two negative control with PBS replacing the first or second antibody, a positive isotype control with the first antibody incubated, and a positive isotype control with only the second fluorescence antibody. Fluorescence index (FI) represents the relative protein expression content. FI = (fluorescence intensity in experimental group-fluorescence intensity in control group)/fluorescence intensity in normal control.

Detection of p-p38 by Western blot analysis. For Western blotting, the cells were washed twice with ice-cold PBS and lysed on ice for $40 \mathrm{~min}$ in a solution containing $50 \mathrm{mM}$ Tris, $1 \%$ Triton $\mathrm{X}-100,0.1 \%$ SDS, $150 \mathrm{mM} \mathrm{NaCl}, 2 \mathrm{mM}$ $\mathrm{Na}_{3} \mathrm{VO}_{4}, 2 \mathrm{mM}$ EGTA, $12 \mathrm{mM}$ ß-glycerolphosphate, $10 \mathrm{mM}$ $\mathrm{NaF}, 16 \mu \mathrm{g} / \mathrm{ml}$ benzamidine hydrochloride, $10 \mu \mathrm{g} / \mathrm{ml}$ phenanthroline, $10 \mu \mathrm{g} / \mathrm{ml}$ aprotinin, $10 \mu \mathrm{g} / \mathrm{ml}$ leupeptin, $10 \mu \mathrm{g} / \mathrm{ml}$ pepstatin, and $1 \mathrm{mM}$ phenylmethylsulfonyl fluoride. The cell lysate was centrifuged at 14,000 x $\mathrm{g}$ for $15 \mathrm{~min}$, and the supernatant fraction was collected for Western blotting. The protein content in the supernatant fraction was determined using the Bradford method (3). Supernatant fraction proteins were separated by SDS-PAGE according to the method of Laemmli (4). The proteins were transferred onto polyvinylidene fluoride membrane. After blocking for $1 \mathrm{~h}$ in $10 \%$ non-fat dry milk in Tris-buffered saline, blots were probed overnight at $4^{\circ} \mathrm{C}$ with a 1:200 dilution of mouse anti-human p-p38, and a 1:1000 dilution of goat anti-human actin (Santa Cruz Biotechnology). Anti-mouse or anti-goat horseradish peroxidase-conjugated secondary antibodies (Amersham Pharmacia, Uppsala, Sweden) were used at a dilution of 1:5000 for chemiluminescence detection, and blots were quantified using ImageQuant software (GDS-8000, UVP, USA).

Immunocytochemistry. The cells were plated in 6-well plates on glass coverslips. After reaching confluence, the monolayer cells were cultured in serum-free medium for $12 \mathrm{~h}$. Then the coverslides with the cells were divided into the control group, the solution group, and the valdecoxib group with concentrations of 400, 200,100, 50 and $25 \mu$ mol.1 $^{1-1}$. The cells were washed twice in PBS and fixed in $4 \%$ paraformaldehyde solution for $20 \mathrm{~min}$ at $4^{\circ} \mathrm{C}$. After blocking with $3 \% \mathrm{H}_{2} \mathrm{O}_{2}$, coverslides were incubated with goat serum for $30 \mathrm{~min}$. Following incubation with anti-p-p38, anti-Fas or anti-FasL antibody conjugated with horseradish peroxidase, the monolayer cells were developed with diaminobenzidine substrate.

Statistical analysis. Results were expressed as mean \pm SD. Statistical significance between different groups was determined by analysis of variance (ANOVA) followed by two-tailed Mann-Whitney U test. A P-value of $<0.05$ was considered statistically significant. Pearson's correlation 
A (F6)[A] Z0004422.LMD : FL3

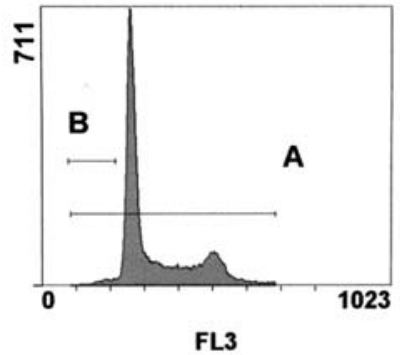

D (F1)[C] Z0004375.LMD : FL3
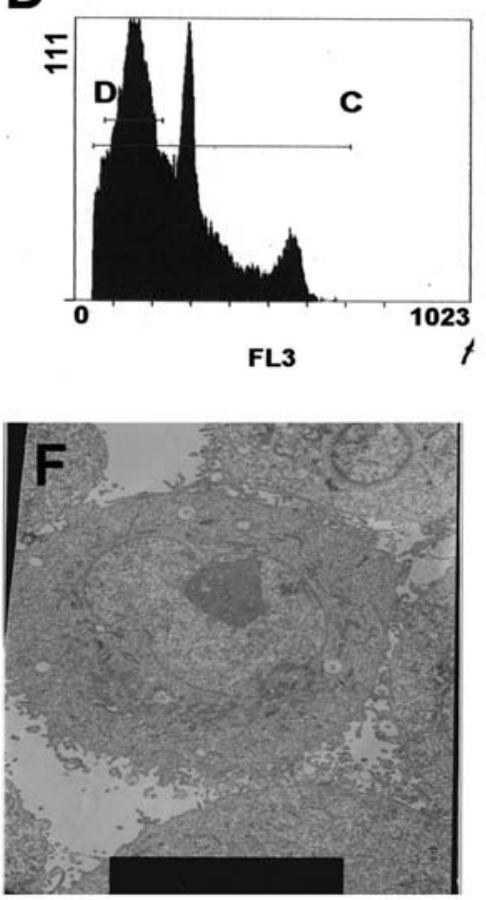

B(F3)[Ungated] Z0004377.LMD : FL3

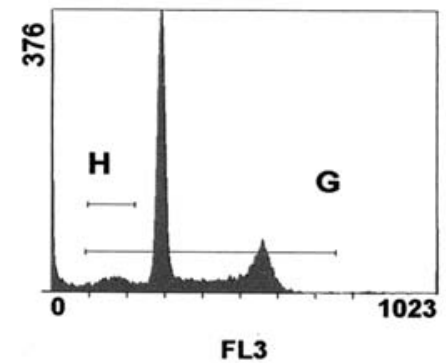

E
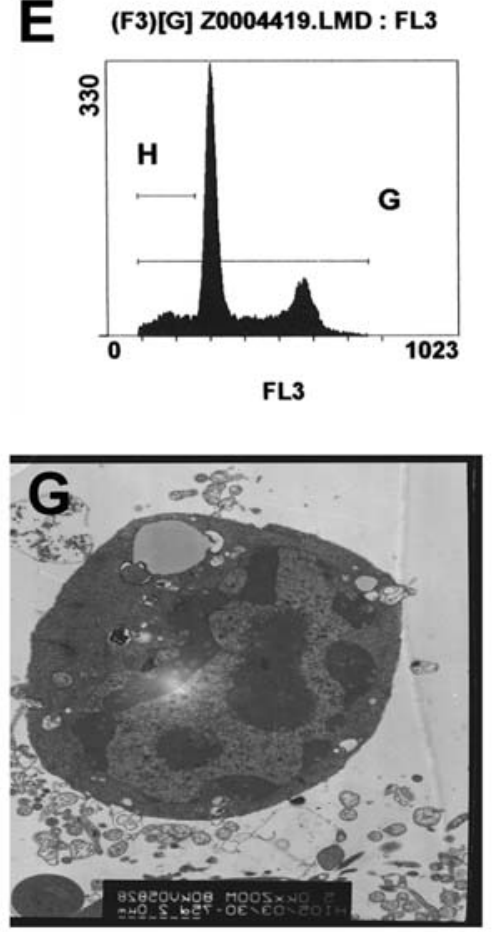

C (F2)[Q] Z0004382.LMD : FL3

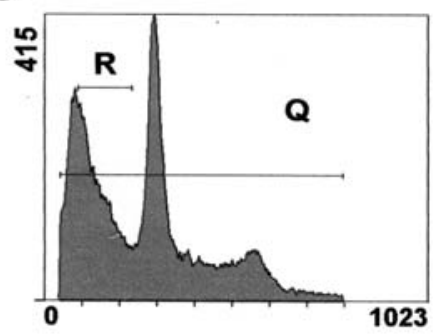

FL3
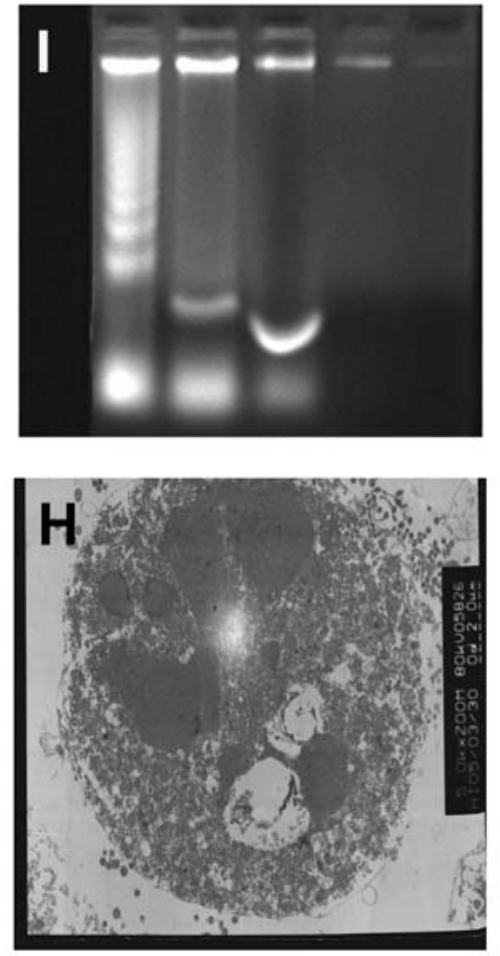

Figure 1. Effect of valdecoxib on apoptosis of the Eca109 cell line in $72 \mathrm{~h}$. By flow cytometry, the spike in front of diploid is called deuto-diploid, representing apoptosis; from A, B, C and D we can conclude that valdecoxib increased the apoptosis rate of Eca109 cells in a concentration-dependent fashion, and E showed that SB203580 decreased the valdecoxib-induced apoptosis. By transmission electron microscopy, concentrated chromatin (G) and nuclear fragmentation $(\mathrm{H})$ could be seen in valdecoxib group compared to solution group (F). (I) DNA fragmentation assay.

coefficient between the expression of p38MAPK, Fas or FasL protein and apoptotic rate or between the expression of p38 and Fas or FasL were analyzed.

\section{Results}

Effect of valdecoxib on the apoptosis of human Eca109 cells. FCM showed that valdecoxib increased the apoptosis rate of Eca109 cells in a concentration-dependent fashion. The rate of apoptosis was increased from $2.38 \pm 0.42 \%$ to between $2.95 \pm 0.83 \%$ and $48.46 \pm 0.73 \%$ (Fig. 1A-D). Electron microscopy showed more apoptotic cells with concentrated chromatin in the valdecoxib-treated group than in the control group (Fig. 1F, G and H). Data from the DNA fragmentation assay showed that valdecoxib induced DNA ladders in Eca109 cells in a dose-dependent manner. Cells treated with $400 \mu \mathrm{mol}^{-1} \mathrm{I}^{-1}$ and $200 \mu \mathrm{mol}^{-1^{-1}}$ valdecoxib for $72 \mathrm{~h}$ exhibited the formation of DNA fragments in Eca109 cells (Fig. 1I). These results are consistent with valdecoxib inducing apoptosis in these cell lines.
Effect of valdecoxib on the expression of Fas and FasL proteins. Immunocytochemical staining showed Fas (Fig. 2A and B) and FasL (Fig. 2C and D) protein expression in the cell membrane and cytoplasm. By FCM, valdecoxib did not have a significant effect on the expression of Fas and FasL proteins at a dose of $25 \mu$ mol..$^{-1}$, but the Fas and FasL proteins were up-regulated in the valdecoxib group compared to the solution group with a dose of 50 400 $\mu \mathrm{mol}^{-1^{-1}}$ in a dose-dependent manner (Fig. 2E and F).

Effect of valdecoxib on p38MAPK expression and activation. RT-PCR showed that the relative expression of p38MAPK was $0.67 \pm 0.07$ after treatment with $25 \mu$ mol. $^{1-1}$ valdecoxib. There was no significant difference compared to the solution control group $(0.64 \pm 0.05)$. However, expression increased as the concentration of valdecoxib increased, especially in the $400 \mu$ mol..$^{-1}$ valdecoxib group (Fig. 3A).

MAPKs participate in diverse cellular functions, such as cell proliferation, apoptosis, cell death and differentiation (5). In the present study, Eca109 cells were treated with various 
A

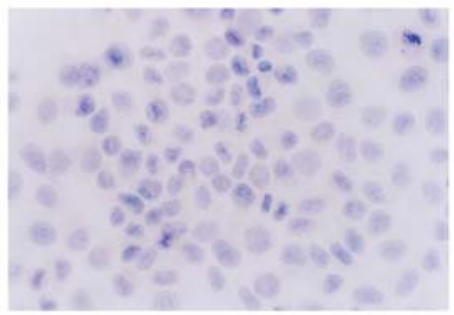

C

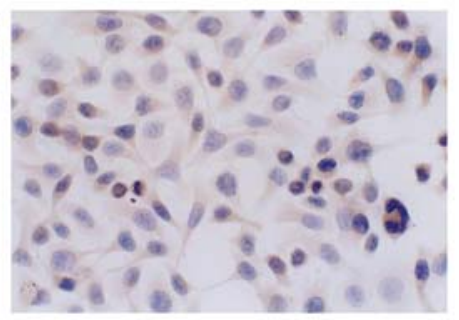

E

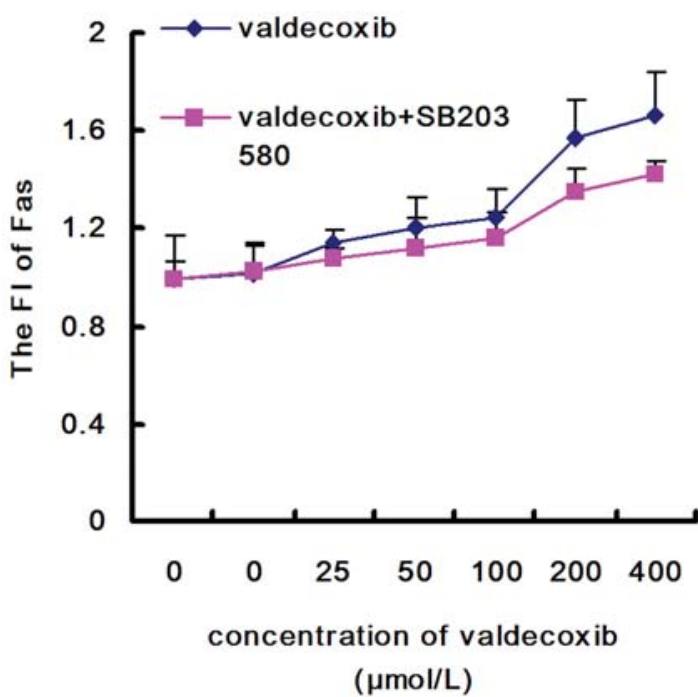

B

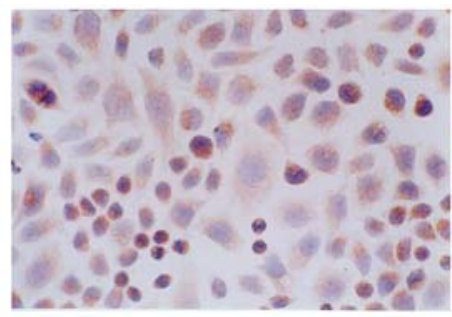

D

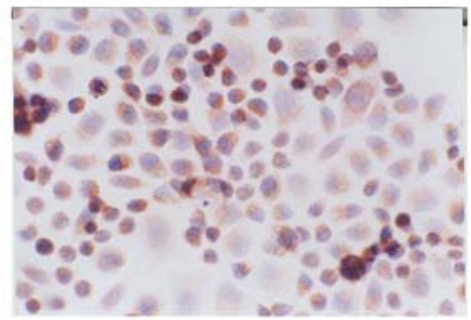

$\mathbf{F}$

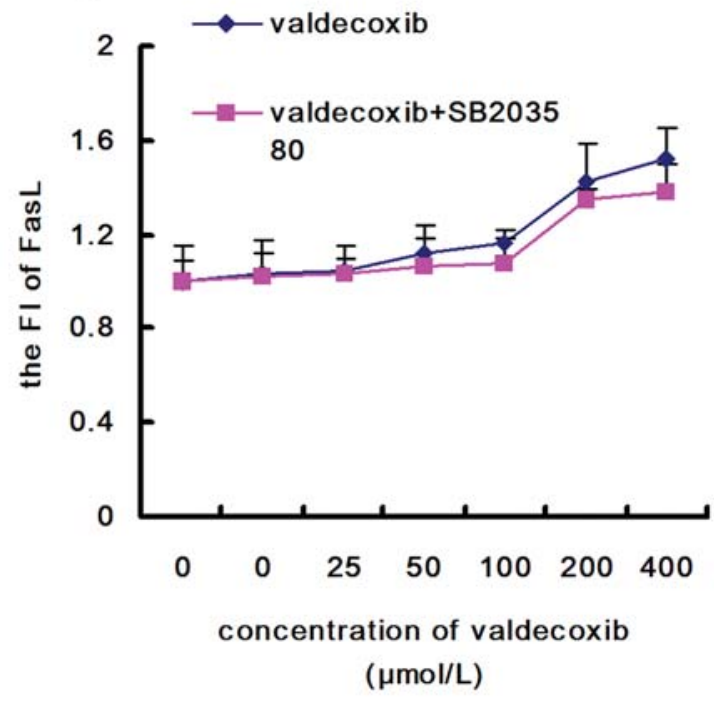

Figure 2. Effect of valdecoxib on the expression of Fas and FasL protein. The positive expression of Fas and FasL protein was in cytomembrane and cytoplasm, there was negative expression in the solvent group (A), while Fas protein expression increased with valdecoxib (B); there was little positive expression in the solvent group (C), while FasL protein expression increased with valdecoxib (ICC, x400). By FCM, blue indicates that valdecoxib upregulated the expression of Fas (E) or FasL (F), while pink shows that treatment with SB203580 decreased the valdecoxib-induced overexpression of Fas and FasL.

A

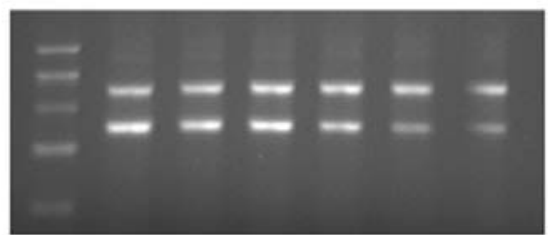

$\begin{array}{lllllll}M & 1 & 2 & 3 & 4 & 5 & 6\end{array}$

B

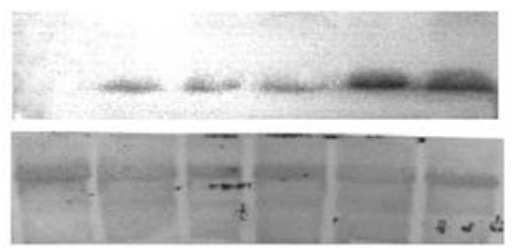

phospho-p38(38KD)

total-p38(38KD)

$\beta$-actin concentrations of valdecoxib for $72 \mathrm{~h}$ and then analyzed for the p38 phosphorylation using phospho-specific antibodies. Fig. 3B showed that valdecoxib induced p38 phosphorylation in Eca109 cells in a concentration-dependent manner. The results suggest that p38 may be involved in the induction of apoptosis by valdecoxib on Eca109 cells.

Immunocytochemical staining showed that p-p38MAPK protein was observed mostly in cell nuclei and that the

Figure 3. Effect of valdecoxib on expression of p38 mRNA and protein. (A) p38 mRNA from human Eca109 cells treated with valdecoxib at different concentrations was analyzed by RT-PCR (A), lanes M, DNA marker; lanes 1, $400 \mu \mathrm{mol} / 1$; lanes 2, $200 \mu \mathrm{mol} / 1$; lanes 3, $100 \mu \mathrm{mol} / 1$; lanes 4, $50 \mu \mathrm{mol} / 1$; lanes 5, $25 \mu \mathrm{mol} / 1$; lanes 6 , solvent, valdecoxib increased p38 mRNA expression in human Eca109 cells. (B) Cells were treated with various concentrations of valdecoxib for $72 \mathrm{~h}$; $\mathrm{p} 38$ phosphorylation was determined by Western blot analysis using phospho-p38 and total-p38 kinase antibodies. Each blot represents one of three independent experiments. 

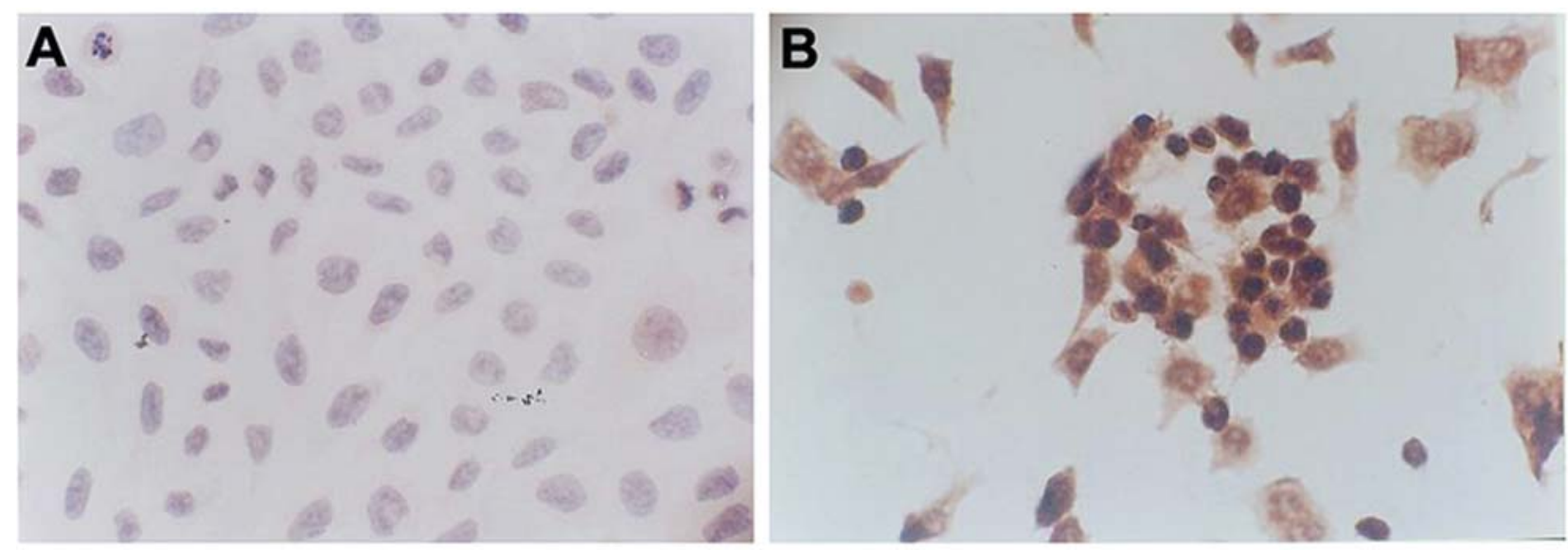

Figure 4. The expression of p-p38MAPK protein in human Eca109 cells treated with valdecoxib (ICC, x400). (A) Control group; (B) valdecoxib group; immunocytochemical staining showed that the positive expressions of p-p38MAPK protein were observed mostly in the cell nucleus, and the expression of pp38 protein was lower in control and solution group,compared to valdecoxib treated group.

A

(F5)[A] Z0009314.LMD : FL1 LOG

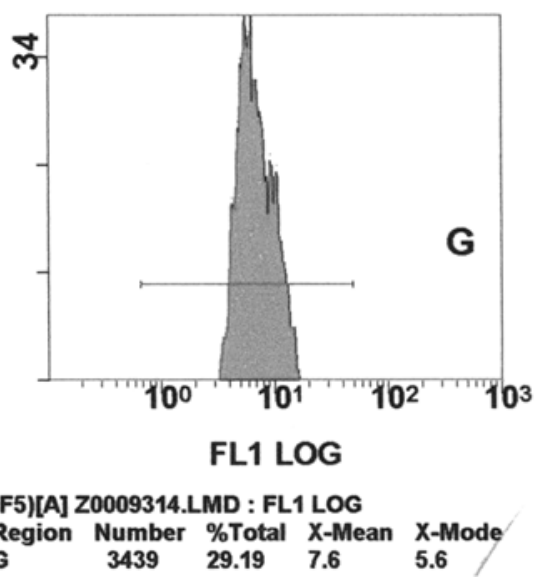

B

(F3)[A] Z0009332.LMD : FL1 LOG

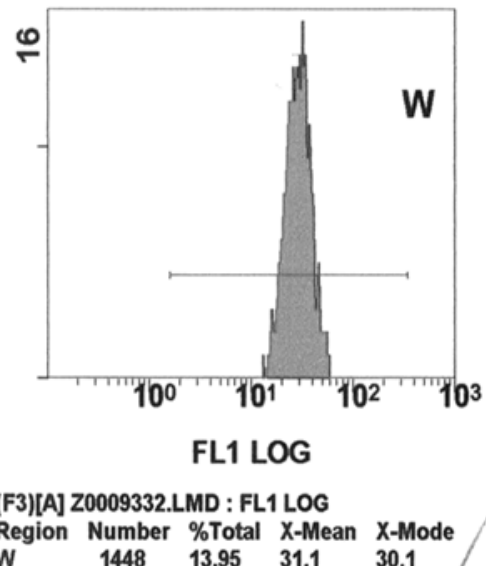

C

(F3)[A] Z0009312.LMD : FL1 LOG

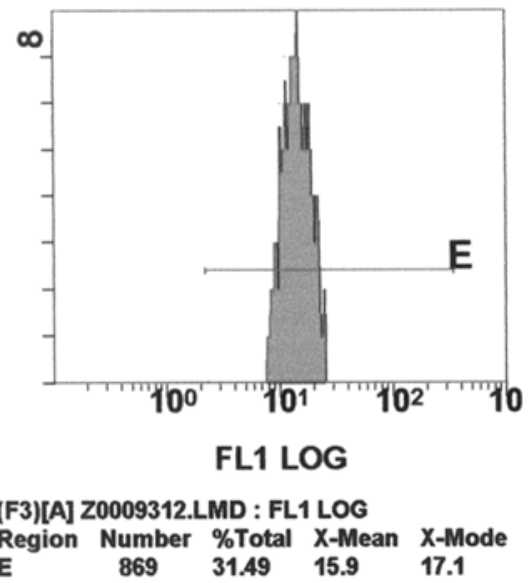

Figure 5. Expression of p38 in different groups by FCM. (A) Solution group; (B) valdecoxib group (400 $\mu \mathrm{mol} / \mathrm{l})$; (C) valdecoxib+SB203580.

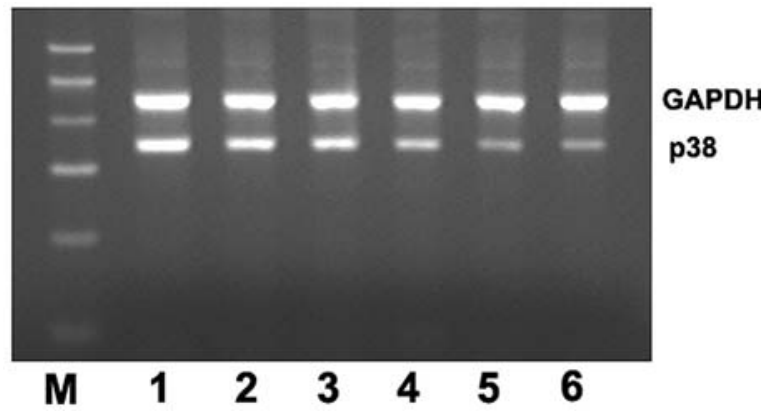

Figure 6. The effect of SB203580 on the p38 mRNA levels in Eca109 cells, using RT-PCR. Lanes M, DNA marker; lanes 1: $400 \mu$ mol..$^{-1}$; lanes 2, $200 \mu$ mol..$^{-1}$; lanes $3,100 \mu$ mol..$^{-1}$; lanes $4,400 \mu$ mol. $.^{-1}+$ SB203580; lanes

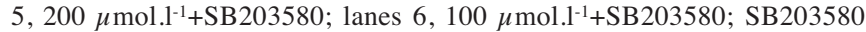
inhibited the p38 mRNA overexpression partly induced by valdecoxib. expression of the p-p38 protein was lower in the control and solution control groups but was increased in the valdecoxib-treated group in a dose-dependent fashion (Fig. 4). FCM showed that the expression of p-p38 protein significantly increased as the concentration of valdecoxib increased after a 72-h treatment (Fig. 5).

Effect of MAPK inhibitors on valdecoxib-induced apoptosis. To further elucidate the role of p38 in valdecoxib-induced apoptosis, we observed the effects of SB203580, a specific p38 inhibitor, on valdecoxib-induced cell apoptosis via FCM. As shown in Fig. 1E, SB203580 significantly augmented the effect of valdecoxib.

Figs. 5 and 6 showed that SB203580 inhibited the p38 mRNA and protein overexpression partly induced by valdecoxib. These results indicate that p38 activation may be involved in inducing apoptosis in Eca109 cells treated 
with valdecoxib. Fig. 2E and F showed that SB203580 inhibited the Fas and FasL protein overexpression partly induced by valdecoxib.

Correlative analysis. The expression of Fas and FasL proteins were positively correlated with the apoptotic rate $(\mathrm{r}=0.876$ and 0.880 , respectively; $\mathrm{P}=0.000$ ). There was also a significant positive correlation between $\mathrm{p} 38 \mathrm{MAPK}$ protein and the ratio of apoptosis $(\mathrm{r}=0.822, \mathrm{P}=0.000)$. In addition, the expression of p38MAPK protein significantly correlated with Fas and FasL protein expression ( $\mathrm{r}=0.951$ and 0.924 , respectively, $\mathrm{P}=0.000$ ).

\section{Discussion}

Recently, inducing cell apoptosis has become a new target for anti-cancer medicine (6). Non-steroid anti-inflammatory drugs (NSAIDs) are widely used chemotherapeutic agents and are known to induce programmed cell death (apoptosis) in a variety of cell types (7). Valdecoxib is a second generation selective COX-2 inhibitor, and our previous experiments have shown that valdecoxib can inhibit the growth of Eca109 cells in a dose- and time-dependent manner, but the precise mechanisms are poorly understood. However, in the present study, we found that valdecoxib up-regulated the expression of Fas and FasL proteins. The DNA ladder assay also confirmed that valdecoxib induced Eca109 cell apoptosis. As shown in Fig. 1D, when $400 \mu \mathrm{mol}^{-1}$ valdecoxib was incubated with Eca109 cells for $72 \mathrm{~h}$, the cell apoptotic rate was $48.46 \%$. These results indicate that valdecoxib can inhibit cancer cell growth in a dose-dependent manner by inducing cell apoptosis.

Considerable data have shown that the COX-2 level is increased in tissues of esophageal cancer, colorectal cancer and pancreas cancer. COX-2 overexpression can induce the incidence of tumors by regulating cellular apoptosis and angiogenesis of capillaries. COX-2-selective inhibitors have been used to treat malignant tumors via COX-2 targeting. Many epidemiological studies have indicated that regular intake of aspirin or other NSAIDs can reduce the risk of suffering from gastrointestinal tract carcinomas, such as colorectal, esophageal and pancreatic carcinomas (8-11). Valdecoxib effectively inhibited COX-2 expression, which correlated with apoptosis of Eca109 cells, but this was most likely not the complete mechanism underlying the induction of apoptosis.

There are many reports on the involvement of $\mathrm{p} 38$, ERK1/2 and JNK kinases in cell proliferation and cell death (12-15). We found that valdecoxib significantly induced p38 and sustained its phosphorylation in Eca109 cells (Fig. 3B), which indicates that the $\mathrm{p} 38$ phosphorylation may be related to the induction of apoptosis by valdecoxib in Eca109 cells. SB203580 is a specific p38 inhibitor, and our results showed that treatment with SB203580 decreased the apoptotic rate of Eca109 cell lines (Fig. 1E). Our results indicate that p38 activation may be involved in inducing valdecoxib-related apoptosis in Eca109 cells.

p38MAPK may regulate cell apoptosis through the following mechanisms: i) up-regulating c-myc expression (16); ii) participating in Fas/FasL-mediated apoptosis (17); iii) inducing p53 phosphorylation (18); iv) activating c-jun and c-fos (19); and v) enhancing TNF expression (20). Fas and FasL protein expression was up-regulated in the valdecoxib group compared with the solution group in a dose-dependent manner. Treatment with SB203580 decreased the overexpression of Fas and FasL. At the same time, the expression of p38MAPK protein significantly correlated with expression of the Fas and FasL proteins. Thus, it appears that valdecoxib could activate the p38MAPK pathway, thus up-regulating Fas and FasL protein expression, which may be one of the mechanisms through which valdecoxib induces apoptosis.

Taken together, our results demonstrate that the inhibitory effect of valdecoxib is due to the induction of apoptosis. Activated p38 may play some role in counteracting the apoptosis-inducing effect of valdecoxib on Eca109 cells. Our results also remind us of the potential toxicity of valdecoxib on normal tissue.

\section{Acknowledgements}

These studies were supported by the Natural Science Foundation of Hebei Province (No. 301354).

\section{References}

1. Nakayama H, Yokoi H and Fujita J: Quantification of mRNA by non-radioactive RT-PCR and CCD imaging system. Nucleic Acids Res 20: 4939, 1992.

2. Yokoi H, Natsuyama S, Iwai M, et al: Non-radioisotopic quantitative RT-PCR to detect changes in mRNA levels during early mouse embryo development. Biochem Biophys Res Commun 195: 769-775, 1993.

3. Bradford MM: A rapid and sensitive method for the quantitation of microgram quantities of protein utilizing the principle of protein-dye binding. Anal Biochem 72: 248-254, 1976.

4. Laemmli UK: Cleavage of structural proteins during the assembly of the head of bacteriophage T4. Nature 227: 680-685, 1970.

5. Towbin H, Staehelin T and Gordon J: Electrophoretic transfer of proteins from polyacrylamide gels to nitrocellulose sheets: procedure and some applications. Proc Natl Acad Sci USA 76: 4350-4354, 1979.

6. Chang L and Karin M: Mammalian MAP kinase signalling cascades. Nature 410: 37-40, 2001

7. Spugnini EP, Porrello A, Citro G and Baldi A: COX-2 overexpression in canine tumors: potential therapeutic targets in oncology. Histol Histopathol 20: 1309-1312, 2005.

8. Zhang P, Crespi VH, Chang E, Louie SG and Cohen ML: Computational design of direct-bandgap semiconductors that lattice-match silicon. Nature 409: 69-71, 2001.

9. Narko K, Zweifel B, Trifan O, Ristimaki A, Lane TF and Hla T: COX-2 inhibitors and genetic background reduce mammary tumorigenesis in cyclooxygenase-2 transgenic mice. Prostaglandins Other Lipid Mediat 76: 86-94, 2005.

10. Narayanan BA, Narayanan NK, Pttman B and Reddy BS: Adenocarcina of the mouse prostate growth inhibition by celecoxib: downregulation of transcription factors involved in COX-2 inhibition. Prostate 66: 257-265, 2006.

11. Guo Y, Harris RB, Rosson D, Boorman D and O'Brien TG: Functional analysis of human ornithine decarboxylase alleles. Cancer Res 60: 6314-6317, 2000.

12. Swamy MV, Herzog CR and Rao CV: Inhibition of COX-2 in colon cancer cell lines by celecoxib increases the nuclear localization of active p53. Cancer Res 63: 5239-5242, 2003.

13. Bonni A, Brunet A, West AE, Datta SR, Takasu MA and Greenberg ME: Cell survival promoted by the Ras-MAPK signaling pathway by transcription-dependent and -independent mechanisms. Science 286: 1358-1362, 1999.

14. Nishina H, Wada T and Katada T: Physiological roles of SAPK/JNK signaling pathway. J Biochem 136: 123-126, 2004. 
15. Won SM, Park YH, Kim HJ, Park KM and Lee WJ: Catechins inhibit angiotensin II-induced vascular smooth muscle cell proliferation via mitogen-activated protein kinase pathway. Exp Mol Med 38: 525-534, 2006.

16. Cho SD, Ahn NS, Jung JW, et al: Critical role of the cJunNH2-terminal kinase and p38 mitogen-activated protein kinase pathways on sodium butyrate-induced apoptosis in DU145 human prostate cancer cells. Eur J Cancer Prev 15: $57-63,2006$

17. Noguchi K, Yamana H, Kitanaka C, Mochizuki T, Kokubu A and Kuchino Y: Differential role of the JNK and p38MAPK pathway in c-Myc- and s-Myc-mediated apoptosis. Biochem Biophys Res Commun 267: 221-227, 2000.
18. Raoul C, Buhler E, Sadeghi C, et al: Chronic activation in presymptomatic amyotrophic lateral sclerosis (ALS) mice of a feedback loop involving Fas, Daxx, and FasL. Proc Natl Acad Sci USA 103: 6007-6012, 2006.

19. Kim H, Kokkotou E, Na X, et al: Clostridium difficile toxin A-induced colonocyte apoptosis involves p53-dependent p21 (WAF1/CIP1) induction via p38 mitogen-activated protein kinase. Gastroenterology 129: 1875-1888, 2005.

20. Varghese J, Chattopadhaya S and Sarin A: Inhibition of p38 kinase reveals a TNF-alpha-mediated, caspase-dependent, apoptotic death pathway in a human myelomonocyte cell line. J Immunol 166: 6570-6577, 2001. 